\title{
AVALIAÇÃO DA DIVERSIDADE GENÉTICA EM ACESSOS DE Psidum spp. VIA MARCADORES RAPD ${ }^{1}$
}

\author{
PATRÍCIA GOMES DE OLIVEIRA PESSANHA ${ }^{2}$, ALEXANDRE PIO VIANA ${ }^{3}$, \\ ANTONIO TEIXEIRA DO AMARAL JÚNIOR ${ }^{4}$, RICARDO MOREIRA DE SOUZA ${ }^{5}$ \\ MILENA CARVALHO TEIXEIRA ${ }^{6}$, MESSIAS GONZAGA PEREIRA ${ }^{7}$
}

RESUMO-O objetivo do presente trabalho foi avaliar a diversidade genética entre 20 acessos de Psidium spp. (UENF 1830 a UENF 1849, UENF- Universidade Estadual do Norte Fluminense) por marcadores RAPD. Vinte e oito primers foram utilizados, gerando um total de 157 bandas. Os marcadores moleculares RAPD foram capazes de revelar a existência de diversidade entre os 20 acessos de Psidium. Para a interpretação dos dados, o índice Nei e Li foi utilizado. Com base na análise do agrupamento hierárquico UPGMA e o método de otimização Tocher, essa diversidade pôde ser observada pela presença de acessos similares e divergentes Termos para indexação: dissimilaridade, marcador molecular, análise multivariada.

\section{ASSESSMENT OF GENETIC DIVERSITY IN ACCESS TO Psidum spp. VIA RAPD MARKERS}

\begin{abstract}
The objective of the present work was to analyze the genetic diversity between 20 guava access (UENF 1830 - UENF 1849) Universidade Estadual do Norte Fluminense - UENF. The genetic dissimilarity was studied using RAPD molecular markers. Twenty eight primers were used, generating a total of 157 bands. The RAPD molecular markers were capable to accurately reveal the existence of diversity among the 20 guava accesses. For data interpretation, the Nei Li. index was used. Based on cluster analysis UPGMA and Tocher, the dissimilarity could be observed by the presence of similar and dissimilar access. Index terms: dissimilarity, molecular marker, multivariate analysis
\end{abstract}

\section{INTRODUÇÃO}

A goiabeira (Psidium guajava L.) é uma entre muitas espécies cultivadas que tem alta diversidade genética. Primeiro, devido à fecundação cruzada preferencialmente da espécie, segundo Alves e Freitas (2007), e, além disso, pela utilização de sementes originárias de progenitores heterozigotos na produção de mudas, a qual leva a uma ampla diversidade genética. Dentro do gênero Psidium, há o araçá (Psidium guineense SW), uma planta silvestre encontrada no Norte Fluminense que tem mostrado resistência ao nematoide Meloidogyne mayaguensis.

O estudo da diversidade genética entre acessos de plantas fornece informações de potenciais genitores a serem utilizados em programa de melhoramento genético vegetal. A forma preditiva de determinar a diversidade genética apresenta como principal vantagem o fato de não ser necessária a obtenção prévia de combinações híbridas, como ocorre em dialelos (COIMBRA et al., 2001).
O conhecimento do grau de variabilidade genética, por meio dos estudos de divergência, torna-se vantajoso no processo de identificação de genes de interesse (MOHAMMADI; PRASANNA, 2003). Outra vantagem é o fato de que, por meio da diversidade genética, podem-se indicar progenitores geneticamente distantes para cruzamentos nos quais procure obter o efeito heterótico na geração híbrida e maior probabilidade de recuperação de segregantes superiores em gerações avançadas (HALLAUER; MIRANDA FILHO, 1981; MOHAMMADI; PRASANNA, 2003; e CRUZ et al., 2004).

Para estudos de diversidade genética, a análise por agrupamento, enquanto método preditivo da heterose, tem sido empregada tanto para características expressas por variáveis quantitativas quanto qualitativas (GOWER, 1971; FRANCO et al., 1998; GONÇALVES et al., 2008; GONÇALVES et al., 2009). Dentre os métodos de agrupamento, UPGMA (Unweighted Pair-Group Method Using an Arithmetic Average) tem tido maior utilização em estudos

\footnotetext{
${ }^{1}$ (Trabalho 074-10). Recebido em: 23-03-2010. Aceito para publicação em: 01-12-2010. Apoio Financeiro: FAPERJ, UENF

${ }^{2}$ Enga . Agro, M.Sc. Campos, RJ, UENF/CCTA/LMGV, CEP 28015-620, E-mail: patriciagop@uenf.br

${ }^{3} E_{n}$ a. Agro, D. Sc., Professor UENF/CCTA/LMGV, CEP 28015-620, E-mail: pirapora@uenf.br

${ }^{4}$ Eng $^{\mathrm{a}}$. Agro, D. Sc., Professor UENF/CCTA/LFIT, CEP 28015-620, E-mail:amaraljr@uenf.br

${ }^{5}$ Eng $^{\mathrm{a}}$. Agro, D. Sc., Professor UENF/CCTA/LMGV, CEP 28015-620, E-mail: ricmsouza@censanet.com.br

${ }^{6} \mathrm{Eng}^{\mathrm{a}}$. Agro, . Campos, RJ, UENF/CCTA/LMGV, CEP 28015-620,, E-mail: mileninhacarvalho@gmail.com

${ }^{7}$ Eng $^{\text {a }}$. Agro, Ph. D Professor UENF/CCTA/LMGV, CEP 28015-620, E-mail: messias@uenf.br
} 
envolvendo recursos genéticos (MOHAMMAD; PRASANNA, 2003).

A tecnologia de marcadores moleculares pode contribuir significativamente para o conhecimento básico da cultura e do caráter estudado, além da geração e desenvolvimento de produtos melhorados (FERREIRA; GRATTAPAGLIA, 1998; BORÉM; CAIXETA, 2009). Neste caso específico, são obtidos dados binários, cujo complemento aritmético da medida de similaridade Jaccard tem maior aceitação pela comunidade científica para acessos pertencentes à mesma espécie (MINGOTI, 2007; SUDRÉ et al., 2006).

Wesh e McClelland (1990) e Williams et al. (1990) introduziram uma técnica que se baseia na detecção de polimorfismo de DNA amplificado ao acaso (RAPD Randon Amplified Polymorphic DNA), usando oligonucleotídeos de dez bases. As análises de RAPD estão baseadas no fato de que cada iniciador dirige a síntese de vários segmentos de DNA, simultaneamente, em diversos pontos no genoma, resultando, assim, em várias bandas com pesos moleculares diferentes, a depender do tamanho do segmento do DNA amplificado. Essa técnica tem-se mostrado eficiente na identificação da variabilidade genética em diversos grupos de plantas e pode ser usada como uma ferramenta auxiliar em programas de melhoramento.

Padilha-Ramírez et al. (2002) empregaram os marcadores tipo RAPD para diferenciação molecular de acessos de Psidium guajava L.. Os marcadores permitiram constatar baixa variabilidade genotípica dos acessos pertencentes ao banco de germoplasma do México.

O objetivo deste trabalho é o estudo da diversidade genética entre vinte acessos de Psidium spp. via marcadores moleculares RAPD.

\section{MATERIAL E MÉTODOS}

Os materiais genéticos foram coletados nas seguintes regiões: São João da Barra-RJ e Bom Jesus do Itabapoana-RJ (Tabela 1).

Cinco folhas jovens de cada acesso foram colhidas em amostras compostas, compreendendo 01 planta/acesso. As cinco folhas correspondentes a cada acesso foram rapidamente reunidas, enroladas em papel-alumínio, identificadas e mergulhadas em gelo seco para que não ocorresse a degradação do DNA. Uma vez no laboratório, esse material foi acondicionado em ultrafreezer, a uma temperatura de $-86{ }^{\circ} \mathrm{C}$. Posteriormente, essas folhas foram maceradas em $\mathrm{N}_{2}$ líquido e acondicionadas em tubos de $15 \mathrm{~mL}$ com tampa, devidamente identificados e armazenados em ultrafreezer.

Cerca de $300 \mathrm{mg}$ de tecido macerado foram transferidos para tubos de 2,0 mL e imersos em $\mathrm{N}_{2}$ líquido para a extração de DNA, de acordo com o protocolo de Doyle e Doyle (1999), com as modificações descritas a seguir.

Foi adicionado a cada tubo $1 \mathrm{~mL}$ do tampão de extração pré-aquecido, contendo $2 \% \mathrm{CTAB}, 104 \mathrm{~mol}$ $\mathrm{L}^{-1} \mathrm{NaCl}, 20 \mathrm{mmol} \mathrm{L}^{-1}$ EDTA, $100 \mathrm{mmol} \mathrm{L}^{-1}$ TrisHCL $(\mathrm{pH} 8,0), 1 \%$ PVP e $2 \% \beta$ - mercaptoetanol. Esse material foi incubado a $65^{\circ} \mathrm{C}$ por 45 minutos e agitado suavemente a cada 10 minutos Em seguida, foi centrifugado a $13.200 \mathrm{rpm}$, durante 5 minutos O sobrenadante (cerca de $800 \mu \mathrm{L}$ ) foi transferido para um novo tubo devidamente identificado ao qual foi adicionado igual volume de clorofórmio: álcool isomílico $(24: 1)$ por aproximadamente 10 minutos, até ficar turvo. A fase orgânica foi separada por centrifugação, a $13.200 \mathrm{rpm}$, por cinco minutos.

O sobrenadante foi recolhido e desproteinizado mais uma vez com clorofórmio: álcool isoamílico (24:1), sendo os ácidos nucleicos precipitados pela diluição de dois terços do volume de isopropanol gelado e incubados por $2 \mathrm{~h} \mathrm{a}-20^{\circ} \mathrm{C}$. O precipitado foi sedimentado por centrifugação, a $13.200 \mathrm{rpm}$, por 10 minutos $\mathrm{O}$ sobrenadante foi removido, e o precipitado, lavado duas vezes com $300 \mu \mathrm{L}$ etanol a 70\%, para retirada de sal presente, e uma vez com $300 \mu 1$ etanol a $95 \%$ (entre cada lavagem, o material foi centrifugado a $13.200 \mathrm{rpm}$, durante 10 minutos). Após o descarte do último sobrenadante, o material foi seco em condições naturais, posteriormente o material foi ressuspendido em $300 \mu \mathrm{L}$ de solução TE (Tris-EDTA-10 $\mathrm{mmol} \mathrm{L}^{-1}$ Tris-HCL, $1 \mathrm{mmol} \mathrm{L}^{-1}$ EDTA, pH 8,0) com RNAse, numa concentração final de $40 \mu \mathrm{g} . \mathrm{mL}^{-1} \mathrm{e}$ incubado em banho-maria a $37{ }^{\circ} \mathrm{C}$ por 30 minutos. Em seguida, adicionaram-se $30 \mu \mathrm{L}$ de $\mathrm{NaCl} 5 \mathrm{~mol} \mathrm{~L}^{-1}$ e $220 \mu \mathrm{L}$ de isopropanol gelado para precipitar o DNA novamente, incubando-se os tubos por $2 \mathrm{~h} \mathrm{a}-20^{\circ} \mathrm{C}$. Logo após, o DNA foi sedimentado por centrifugação, a $13.200 \mathrm{rpm}$, por 10 minutos, e lavado duas vezes com etanol a $70 \%$ e uma vez com etanol a 95\%. Após seco, o precipitado final foi suspenso em $150 \mu \mathrm{L}$ de água ultrapura (milli q).

A quantificação foi realizada em géis de agarose a $0,8 \%(\mathrm{p} / \mathrm{v})$, submetidos à eletroforese. Alíquotas de DNA de cada amostra foram aplicadas nos poços do gel, com um marcador com concentração conhecida $(\lambda)$. A concentração das amostras foi estimada por comparação visual da intensidade de fluorescência das bandas do DNA $(\lambda)$. Os géis foram visualizados no equipamento Eagle Eye II (Stratagene) após a coloração com $10 \mu \mathrm{L}$ de brometo de etídeo $\left(10 \mathrm{mg} \mathrm{mL}^{-1}\right)$, diluídos em $100 \mathrm{~mL}$ de 
tampão TEB 1X. Posteriormente, o DNA foi diluído

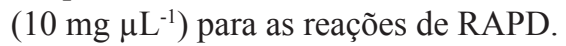

Após a quantificação do DNA, as reações de amplificação foram feitas em termociclador modelo Mastercycler gradient (Eppendorf), num volume

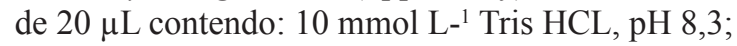
$50 \mathrm{mmol} \mathrm{L}-{ }^{-1} \mathrm{KCl} ; 2,4 \mathrm{mmol} \mathrm{L}-{ }^{-1} \mathrm{MgCl}_{2} ; 100 \mu \mathrm{M}$ dATP, dCTP, dGTP e dTTp; $0,4 \mu \mathrm{M}$ de iniciadores; 20 ng de DNA genômico e 0,75 unidade de Taq DNA polimerase. Foram utilizados microtubos nos quais foram adicionados todos os demais reagentes nas concentrações mencionadas, cada mix com um iniciador diferente. Desta solução, foram retirados $18 \mu \mathrm{L}$ e adicionados aos microtubos, totalizando os $20 \mu \mathrm{L}$ da reação.

As reações foram submetidas a 45 ciclos de amplificação após desnaturação inicial a $95^{\circ} \mathrm{C}$, por 4 minutos. Cada ciclo constitui de 1 minutos a $94^{\circ} \mathrm{C}, 1$ min a $36^{\circ} \mathrm{C}$ e 2 minutos a $72^{\circ} \mathrm{C}$. Ao final de 45 ciclos, foi realizada uma extensão final de 7 minutos, a $72^{\circ} \mathrm{C}$.

Os produtos de amplificação foram submetidos à eletroforese ( $100 \mathrm{~V}$ por 90 minutos) em géis de agarose a $1,4 \%(\mathrm{p} / \mathrm{v})$, utilizando o tampão de corrida TAB 1X. Os géis foram corados com brometo de etídeo e fotografados sob luz UV (Eagle Eye II Stratagene).

Foi feita, de forma prévia, uma triagem de iniciadores, utilizando-se de cinquenta e um, tendo como critérios de escolha, em ordem decrescente de prioridade, um grande número de bandas totais, um grande número de bandas polimórficas. Assim, selecionaram-se como polimórficos os iniciadores da Operon Technologies, Inc. OPA3, OPA5, OPA6, OPA8, OPA9, OPA10, OPA12, OPA15, OPA18, OPA19, OPA20, OPAB3, OPAB4, OPAB8, OPAC4, OPAC6, OPAC7, OPAW2, OPAW7, OPAW9, OPAW10, OPAW20, OPD2, OPD12, OPD13, OPS7, OPV6 e OPV12.

Os dados foram obtidos pela avaliação visual das bandas mais evidentes e consistentes nos 20 indivíduos avaliados. Foi elaborada matriz de dados binários, em que o número 1 corresponde à presença da banda, o zero, à ausência da banda e, quando não era possível determinar se a banda estava presente ou não em função da não amplificação de um acesso para aquele iniciador, foi computado como 2 .

Na interpretação das análises moleculares, foi utilizado o complemento aritmético do índice Nei e Li (CRUZ; CARNEIRO, 2003). Posteriormente, foi adotado o método hierárquico UPGMA para o agrupamento. No procedimento analítico, partindose da matriz de distância genética, procedeu-se a sucessivas identificações dos genótipos mais próximos, a partir do par mais semelhante, até que se estabeleceu o dendrograma. E o método de otimização Tocher, com a formação de grupos.

Os dados foram analisados pelo Programa Genes (CRUZ, 2006), dendrograma obtido pelo método UPGMA, gerado com auxílio do Programa Mega 4 (KUMAR et al., 2008), as correlações cofenéticas (SOKAL; ROHLF, 1962) pelo Programa R (REIS; RIBEIRO JUNIOR, 2007) e o Pseudo t ${ }^{2} \mathrm{e}$ Pseudo $\mathrm{F}_{2}$, conforme preconizado por Duda e Hart (1973) e Calinski e Harabasz (1974) pelo Programa SAS (MINGOTI, 2007).

\section{RESULTADOS E DISCUSSÃO}

Cada iniciador produziu bandas de intensidade variável, facilmente detectadas e bandas inespecíficas que foram descartadas. Os 28 iniciadores produziram 157 bandas. Destas, 155 foram polimórficas, ou seja, em média, cada iniciador gerou aproximadamente 5 bandas polimórficas. O número total de bandas polimórficas por iniciadores variou 1 a 7 , sendo o iniciador OPA3 o mais polimórfico, gerando 7 bandas (Tabela 2).

Para Gomes Filho et al. (2010), os iniciadores OPA 03, OPA 05, OPA 10, OPA 12 e OPC 19 são indicados para estudos de diversidade em goiabeiras, utilizando o marcador do tipo RAPD, pois apresentaram mais polimorfismo.

Detectou-se divergência genética entre acessos de goiabeira com base na técnica do RAPD, confirmando os resultados obtidos por Padilha-Ramírez et al. (2002) com goiaba, no México. Utilizando o índice de Nei e Li, identificaram-se como mais distantes os acessos UENF1835 e UENF1841, enquanto os acessos UENF1835 e UENF1847 foram os mais similares (Figura 1).

Padilha-Ramírez et al. (2002), utilizando-se de marcadores RAPD, observaram reduzida variabilidade genotípica dos acessos, ou seja, os acessos pertencentes ao banco de germoplasma do México apresentaram $60 \%$ de bandas polimórficas, resultado este inferior ao encontrado neste trabalho, cujo polimorfismo foi de $97,5 \%$.

O ponto de corte do dendrograma obtido pelo programa SAS, através do Pseudo $\mathrm{F}_{2}$ e Pseudo $\mathrm{t}^{2}$, possibilitou a formação de dois grupos (Figura1). $\mathrm{O}$ grupo I foi constituído pelo maior número de acessos, totalizando 14 acessos, ou seja, 70\% do total. Este foi o grupo que apresentou maior número de bandas polimórficas, evidenciando maior variabilidade genética em relação ao outro grupo. Embora formados exclusivamente a partir dos perfis moleculares, os dois grupos apresentaram algumas características peculiares, como pertencerem a espécies diferentes. 
No método de agrupamento hierárquico UPGMA, o grupo I reuniu os acessos UENF1830, UENF1831, UENF1832, UENF1833, UENF1834, UENF1835, UENF1836, UENF1837, UENF1838, UENF1843, UENF1844, UENF1846, UENF1847 e UENF1849, pertencentes à espécie Psidium guajava L., provenientes do município de Bom Jesus do Itabapoana-RJ. Devido ao grande número de acessos no grupo I, formaram-se cinco subgrupos. O subgrupo I.I reuniu os acessos UENF 1835, UENF 1847, UENF 1836, UENF 1834 e UENF 1832. O subgrupo I.II reuniu os acessos UENF 1833, UENF1837 e UENF 1846. O subgrupo I.III reuniu os acessos UENF 1838 e UENF 1849. O subgrupo I.IV reuniu os acessos UENF 1843 e UENF 1844. Por fim, o subgrupo I.V reuniu os acessos UENF 1831 e UENF 1830.

As características dos acessos do subgrupo I. I são plantas com folhas finais e rugosas e frutos de polpa vermelha e amadurecimento uniforme. Os acessos do subgrupo I. II apresentam plantas de ciclo tardio e frutos de polpa vermelha; o subgrupo I. III são frutos de penca unitária e polpa vermelha e roxa; o subgrupo I. IV são frutos de polpa vermelha, grandes, periforme, e a planta de crescimento horizontal; e o subgrupo I.V apresenta plantas de ciclo precoce e frutos de polpa vermelha.O alto grau de diversidade genética dos acessos, encontrada no grupo I, deve-se ao sistema reprodutivo da espécie Psidium guadava L., pois segundo Alves e Freitas (2007), a forma mais frequente de polinização em goiaba é a fecundação cruzada, ou seja, a goiaba possui maior taxa de fecundação cruzada quando comparada à autofecundação. Além disso, a utilização de sementes originárias de progenitores heterozigotos na produção de mudas leva a uma ampla diversidade genética devido à população $\mathrm{F} 1$ estar comportando-se como F2 (população segregante).

O grupo II reuniu os acessos UENF1839, UENF1840, UENF1841, UENF1842, UENF1845 e UENF1848, pertencentes à espécie Psidium guineense SW; o acesso UENF1845 deveria enquadrar-se melhor no grupo I. Segundo Costa e Forni-Martins (2007), diversos Psidium neotropicais têm sua origem da hibridização do $P$. guajava L. e $P$. guineense Sw. Estas espécies apresentam o mesmo número de cromossomos. O acesso UENF1845 pode apresentar uma similaridade genética maior ao $P$. guineense $\mathrm{SW}$ entre os demais acessos de P. guajava L. O acesso UENF1848 apresenta resistência ao nematoide das galhas Meloidogyne mayaguensis, e os acessos UENF1839, UENF1840, UENF1841 e UENF1842 são plantas procedentes do acesso UENF 1848 via semente. Esse baixo grau de diversidade do grupo
II pode estar relacionado com barreiras pré e pószigóticas, portanto necessita-se de mais estudos sobre o sistema reprodutivo da família Myrtaceae, principalmente das espécies silvestres para possibilitar a introgressão de genes de interesse.

O coeficiente de correlação cofenética (CCC) (SOKAL; ROHLF, 1962) obtido no UPGMA foi o máximo $(0,92)$ em relação aos métodos hierárquicos de Ward $(0,82)$ e vizinho mais próximo (SL) $(0,90)$. Gonçalves et al. (2008), trabalhando com quarenta acessos de tomates no banco de germoplasma da UENF, obteviveram CCC maiores no método de agrupamento UPGMA em relação aos métodos de agrupamento SL e Ward. Segundo Mohammad e Prasanna (2003), quanto maior CCC, menor será a distorção provocada ao agrupar os acessos. Portanto, o método hierárquico UPGMA foi o que melhor explicou a diversidade genética entre os acessos de goiaba e araçá, porque apresentou maior CCC dentro dos métodos hierárquicos.

O método de otimização de Tocher possibilitou a formação de seis grupos (Tabela 3). Comparando-se o resultado obtido pelo método hierárquico UPGMA com o de Tocher, não se observou concordância entre os números de grupos. Sendo assim, o número de acessos a cada método foi discordante.

No método de otimização Tocher, o grupo I foi constituído pelo maior grupo de acessos, totalizando doze acessos, ou seja, 60\% do total (Tabela 3); o grupo II, os quatro acessos provenientes da planta UENF 1848; os demais grupos apresentaram apenas um acesso (Tabela1). Para Vieira et al. (2005), os grupos formados por apenas um indivíduo apontam na direção de que tais acessos sejam mais divergentes em relação aos demais, como pôde ser observado neste trabalho. As espécies analisadas ficaram dispostas em grupos diferentes. Os acessos de Psidium guineense SW ficaram no grupo II (UENF 1839, UENF 1840, UENF 1841 e UENF 1842), e no grupo V, o acesso UENF 1848, e os acessos de Psidim guajava L. nos demais grupos.

Quanto ao cruzamento entre os acessos, é possível indicá-lo entre UENF 1844 e UENF 1848, sendo o acesso UENF 1844 com frutos de polpa vermelha e altamente suscetível ao Meloidogyne mayaguensis, e o acesso UENF 1848, silvestre, resistente ao Meloidogyne mayaguensis. Porém, além da distância genética, é necessário saber se os acessos escolhidos formarão sementes híbridas viáveis. Outros cruzamentos indicados são os cruzamentos intraespecíficos entre os acessos do grupo I. 


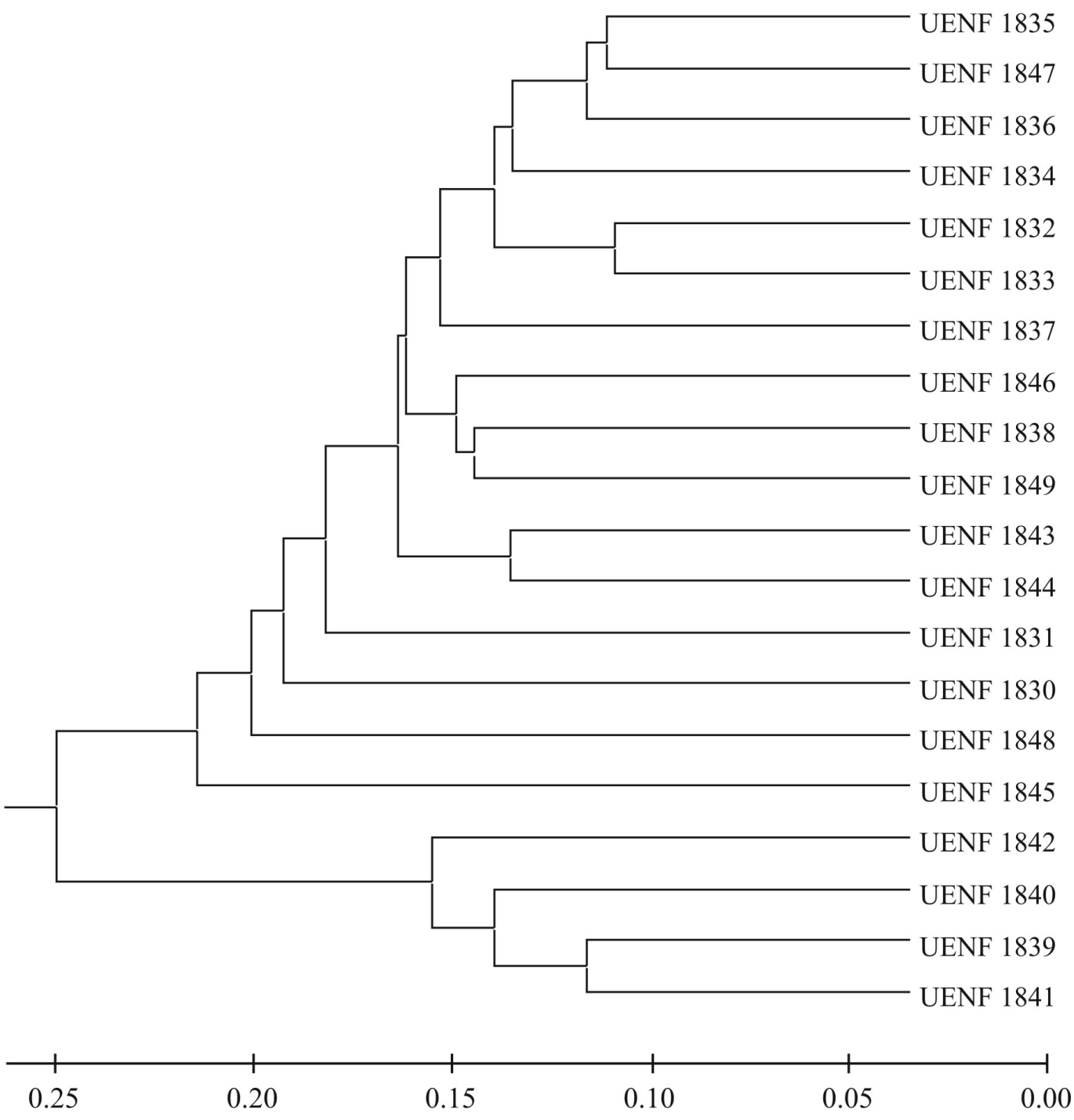

FIGURA 1 - Dendrograma obtido pelo método UPGMA a partir das medidas de dissimilaridade genética entre 20 acessos de Psidum spp. caracterizado por marcadores RAPD. 
TABELA 1 - Acessos de Psidium spp. utilizados para estudo de RAPD e diversidade genética.

\begin{tabular}{llll}
\hline Código & Características & Espécie & Fonte do material \\
\hline
\end{tabular}

UENF 1830, UENF 1831, UENF 1832,

UENF 1833, UENF 1834, UENF 1835,

UENF 1836, UENF 1837, UENF 1843,

UENF 1844, UENF 1845, UENF 1846,

Cor de polpa vermelha

Psidium guajava $\mathrm{L}$

A, B

UENF 1847 e UENF 1849.

\section{UENF1838}

Cor de polpa branca Psidium guajava $\mathrm{L}$

A

UENF 1839, UENF 1840, UENF 1841, Resistente a Psidium guineense

UENF 1842 e UENF 1848.

nematoide

SW

$\mathrm{B}, \mathrm{C}$

A- Sítio Providência, Bom Jesus do Itabapoana-RJ; B- Viveiro Itamudas, Bom Jesus do Itabapoana-RJ; C- São João da Barra-RJ.

TABELA 2 - Lista dos códigos e as sequências dos primers e seus respectivos números de bandas polimórficas e monofórmicas obtidas na análise de DNA, molde extraído de acessos de goiaba e araçá.

\begin{tabular}{|c|c|c|c|}
\hline Primers & $\begin{array}{l}\text { Sequência dos Iniciadores } \\
\qquad 5^{\prime}=>3\end{array}$ & Bandas Polimórficas & Bandas monomórficas \\
\hline OPA03 & AGTCAGCCAC & 7 & 0 \\
\hline OPA05 & AGGGGTCTTG & 5 & 0 \\
\hline OPA06 & AGGGGTCTTG & 6 & 0 \\
\hline OPA08 & GAAACGGGTG & 3 & 0 \\
\hline OPA09 & GTGACGTAGG & 2 & 0 \\
\hline OPA10 & GGGTAACGCC & 3 & 0 \\
\hline OPA12 & CAATCGCCGT & 5 & 0 \\
\hline OPA15 & TCTGTGCTGG & 3 & 0 \\
\hline OPA18 & GACCGCTTGT & 4 & 0 \\
\hline OPA19 & AGGTGACCGT & 5 & 0 \\
\hline OPA20 & CAAACGTCGG & 2 & 0 \\
\hline OPAB03 & TGGCGCACAC & 5 & 0 \\
\hline OPAB04 & GGCACGCGTT & 4 & 1 \\
\hline OPAB08 & GTTACGGACC & 5 & 0 \\
\hline OPAC04 & ACGGGACCTG & 5 & 0 \\
\hline OPAC06 & CCAGAACGGA & 4 & 0 \\
\hline OPAC07 & GTGGCCGATG & 4 & 0 \\
\hline OPAW02 & TCGCAGGTTC & 5 & 0 \\
\hline OPAW07 & AGCCCCCAAG & 5 & 0 \\
\hline OPAW009 & ACTGGGTCGG & 5 & 0 \\
\hline OPAW10 & GGTGTTTGCC & 4 & 1 \\
\hline OPAW20 & TGTCCTAGCC & 4 & 0 \\
\hline OPD02 & GGACCCAACC & 4 & 0 \\
\hline OPD12 & CACCGTATCC & 6 & 0 \\
\hline OPD13 & GGGGTGACGA & 5 & 0 \\
\hline OPS07 & TCCGATGCTG & 3 & 0 \\
\hline OPV06 & ACGCCCAGGT & 4 & 0 \\
\hline OPV12 & ACCCCCCACT & 5 & 0 \\
\hline Total & & 155 & 2 \\
\hline
\end{tabular}


TABELA 3 - Acessos de Psidium spp. caracterizados com marcadores moleculares RAPD e agrupados pelo método de otimização Tocher.

\begin{tabular}{c|l}
\hline \multicolumn{1}{l}{ Grupos } & \multicolumn{1}{c}{ Acessos } \\
\hline I & UENF1832, UENF1833, UENF1834, UENF1835, UENF1836, UENF1837, \\
II & UENF1838, UENF1843, UENF1844, UENF1846, UENF1847 e UENF1849 \\
III & UENF1831, UENF1840, UENF1841 e UENF1842 \\
IV & UENF1845 \\
V & UENF1848 \\
VI & UENF1830 \\
\hline
\end{tabular}

\section{CONCLUSÕES}

1-Os resultados mostram que os marcadores moleculares RAPD são eficazes em revelar a existência de diversidade genética entre os vinte acessos de Psidium spp.

2-O método de agrupamento hierárquico UPGMAé o que melhor explica diversidade genética dos acessos neste trabalho.

\section{REFERÊNCIAS}

ALVES, J.E.; FREITAS, B.M. Requerimento de polinização da goiaberia. Ciência Rural, Santa Maria, v.37, n.5, p.1281-1286, 2007.

BORÉM, A.; CAIXETA, E. T. Marcadores moleculares. Viçosa: UFV, 2009. V.2, p. 585

CALINSKI, T.; Harabasz, J. A dendrite method for cluster analysis. Communications in Statistics, Londres, v.3, p.1-27, 1974.

COIMBRA, R.R.; MIRANDA, G.V.; MOREIRA, G.R.; SILVA, D.J.H.; CRUZ, C.D.; CARNEIRO, P.C.S.; SOUZA, L.V.; GUIMARÃES, L.J.M.; MARCASSO, R.C.; CANIATO, F.F. Divergência genética de cultivares de milho baseada em descritores qualitativos. In: SIMPÓSIO DE RECURSO GENÉTICO PARA AMÉRICA LATINA E CARIBE, 3.; 2001. Londrina. Anais... p. 401-402.
COSTA, I.R.da; FORNI-MARTINS, E. R. Karyotype analysis in South American species of Myrtaceae. Botanical Journal of the Linnean Society, London, v. 155, p. 571-580, 2007.

CRUZ, C.D. Programa genes (versão Windows): aplicativo computacional em genética e estatística. Viçosa: UFV, 2006. p.648.

CRUZ, C. D.; CARNEIRO, P.C.S. Modelos bimétricos aplicados ao melhoramento genético. Viçosa: UFV, 2003. v.2, p. 585.

CRUZ, C.D.; REGAZZI, A. J.; CARNEIRO, P.C.S. Modelos Biométricos aplicados ao Melhoramento Genético. Viçosa: UFV, 2004. v.1, p.480.

DOYLE, J.J.; DOYLE, J.J. Isolation of plant DNA from fresh tissue. Focus, Nairobi, v.12, p.13-15, 1990. (mudar no texto Doyle e Doyle (1999) para Doyele e Doyle (1990), p. 4 , linha 87)

DUDA, R.O.; HART, P.E. Pattern classification and scene analysis. New York: John Wiley \& Sons, 1973. p.189-225.

FERREIRA, M.E.; GRATTAPAGLIA, D. Introdução ao uso de marcadores moleculares em análise genética. Brasília: EMBRAPA/ CENARGEN, 1998. v.3, p.220.

FRANCO, J.; CROSSA, J.; VILLASENÕR, J.; TABA, S. Classifying genetic resources by categorical and continuous variables. Crop Science, Madison, v.38, p.1688-1696, 1998. 
GOMES FILHO, A.; OLIVEIRA, J.O.de; VIANA, A.P.; SIQUEIRA, A.P. de O.; OLIVIERA, M.G.; PEREIRA, M.G. Marcadores moleculares RAPD e descritores morfológicos na avaliação da diversidade genética de goiabeiras (Psidium guajava L.). Acta Scientiarum Agronomy, Maringá, v.32, n. 4, 2010. (no prelo)

GONÇALVES, L.S.A.; RODRIGUES, R.; AMARAL JÚNIOR, A. T.; KARASAWA, M.; SUDRÉ, C.P. Comparison of multivariate statistical algorithms to cluster tomate heirloom accessions. Genetics and Molecular Research, Ribeirão Preto, v.7, n.4, p.1289-1297, 2008.

GONÇALVES, L.S.A.; RODRIGUES, R.; AMARAL JUNIOR, A.T. DO; KARASAWA, M.; SUDRE, C.P. Heirloom tomato gene bank: assessing genetic divergence based on morphological, agronomic and molecular data using a Ward-modified location model. Genetics and Molecular Research, Ribeirão Preto, v. 8, n.1, p.364-374, 2009.

GOWER, J.C. A general coefficient of similarity and some of its properties. Biometrics, Hoboken, v. 27 p.857-874, 1971.

HALLAUER, A.R.; MIRANDA FILHO, J.B. Quantitative genetics in maize breeding. Ames: Iowa State University Press, 1981. p.468.

KUMAR, S.; DUDLEY, J.; NEI, M.; TAMURA, K. MEGA: A biologist-centric software for evolutionary analysis of DNA and protein sequences. Briefings in Bioinformatics, Oxford, v. 9, p.299-306, 2008.

Mingoti, S. A. Análise de dados através de métodos de estatística multivariada. Belo Horizonte: UFMG, 2007. p. 295.
MOHAMMAD, S.A.; PRASANNA, B.M. Analysis of genetic diversity in crop plants- Salient statistical tools and considerations. Crop Science, Madison, v.43, p.1235-1248, 2003

PADILHA-RAMÍREZ, J.S.; GONZÁLEZ-GAONA, E.; ESQUIVEL-VILLAGRANA, F.; MERCADOSILVA, E.; HERNANDEZ-DELGADO, S.; MAYEK-PÉREZ, N. Caracterización de germoplasma sobresaliente de guayabo de la región CalvilloCanõnes, Mexico. Revista Fitotecnia Mexicana, Chapinga, v.25, n.4, p.393-399, 2002.

REIS, G.M.; RIBEIRO JR., J. I. Como baixar e instalar o Programa R. Viçosa: UFV, 2007.

SOKAL, R.R.; ROHLF, F.J. The comparison of dendograms by objetive methods. Taxonomy, Berlim, v.11, p.33-40, 1962.

SUDRÉ, C.P.; CRUZ, C.D.; RODRIGUES, R; RIVA, E.M; AMARAL JÚNIOR, A.T; SILVA, D.J.H; PEREIRA, T.N.S.. Variáveis multicategóricas na determinação da divergência genética entre acessos de pimenta e pimentão. Horticultura Brasileira, Campinas, v. 24, p. 88-93, 2006.

VIEIRA, E.A.; FIALHO, J.F.; FALEIRO, F.G.; FUKUDA, W.M.G.; JUNQUEIRA, N.T.V. Variabilidade genética para caracteres morfológicos entre acessos do banco de germoplasma de mandioca da Embrapa Cerrados. In: CONGRESSO BRASILEIRO DE MANDIOCA, 11., 2005, Campo Grande. Anais... CD-ROM

WESH, J.; MCCLELLAND, M. Fingerprinting genomes using PCR with arbitrary primers. Nucleic Acids Research, Oxford, v.18, p.7213-7218, 1990.

WILLIAMS, J.G.K.; KUBERLIK, A.R.; RAFALSKI, J.A.; TINGEY, S.V. DNA polymorfidm amplified by arbitrsry primers are useful as genetic markers. Nucleic Acids Research, Oxford, v.18, p.6531-6535, 1990. 